NOTA CIENTÍFICA

\title{
Optimización del test de micronúcleos en linfocitos cultivados usando una metodología de gradiente y frotis
}

\section{Improving the micronuclei test in cultured lymphocytes by gradient and cell spreading methodology}

1 Centro de Genética y Biología Molecular. Facultad de Medicina Humana, Universidad de San Martín de Porres, Alameda del Corregidor 1531, La Molina, Lima, Perú. Tel. 5113652300 anexo 152 2 Facultad de Ciencias Biológicas, Universidad Nacional Mayor de San Marcos

* Autor para correspondencia

Email Ricardo Fujita:

rfujita@rcp.net.pe

Email Erika Castillo:

erikita_cast@hotmail.com

Email María Luisa Guevara-Fujita:

mguevara1@usmp.edu.pe

Presentado: $\quad 11 / 01 / 2011$

Aceptado: $\quad 19 / 06 / 2011$

Publicado online: 25/08/2011

\author{
Erika Castillo ${ }^{1,2}$, María Luisa Guevara-Fujita ${ }^{1}$ y Ricardo Fujita ${ }^{1 *}$
}

\section{Resumen}

El test de micronúcleos en cultivo de linfocitos es una prueba validada para estudiar mutagenicidad. Consiste en detectar material nuclear interfásico dañado, producto de fragmentación cromosómica o errores de división nuclear en 2000 células binucleadas con citoplasma definido. El protocolo estándar deriva de la preparación citológica de cromosomas de sangre periférica con solución hipotónica, lavados de fijador y goteo de láminas. Nosotros proponemos modificaciones para mejorar el número y la observación de los micronúcleos. Primero se purifica linfocitos de glóbulos rojos antes del cultivo, luego de 72 horas, se elimina la solución hipotónica y los lavados repetidos con fijador, y finalmente se coloca las muestras en láminas por frotis en vez de goteo. Con las modificaciones obtenemos mas células binucleadas bien definidas (un promedio de 8 veces más por lámina) mejorando la eficiencia de este test.

Palabras clave: biomonitoreo humano; Proyecto HUMN; genotoxicidad; citogenética; protocolo.

\section{Abstract}

The micronuclei test in lymphocyte culture is a validated procedure to study mutagenicity. It consists in detecting damaged interphasic nuclear material produced by chromosome fragmentation or nuclear division errors in 2000 binucleated cells with well defined cytoplasm. Standard protocol derives from blood chromosome preparation with hypotonic and fixing solutions as well as preparing slides by dropping fixed cells. We modified the protocol to improve the number and quality of micronuclei. First, lymphocytes are separated from red cells before culture. After 72 hours, hypotonic and repeated fixer washing steps are eliminated. Cells are put onto slides by spreading instead of dropping. With these modifications we obtained more (about 8 times per slide) and better defined binucleated cells to help micronuclei detection.

Keywords: Human biomonitoring; HUMN Project; genotoxic; Cytogenetic; Protocol.
Los micronúcleos $(\mathrm{MN})$ son corpúsculos citoplasmáticos esféricos, detectados en interfase, más pequeños y con las mismas características morfológicas que el núcleo celular; se originan por pérdida de fragmentos cromosómicos o cromosomas enteros durante la división nuclear y tienen valor en el diagnóstico de genotoxicidad. El test de micronúcleos registra sólo las células binucleadas por bloqueo de la citocinesis con citochalasina $\mathrm{B}$ (CBMN), descartando el conteo de mononucleadas, trinucleadas, tetranucleadas, etc. Este artificio permite determinar qué células han estado expuestas al mutágeno o sustancia a probar y han pasado recientemente primera división.

En comparación con el test de micronúcleos, el análisis de aberraciones cromosómicas en metafases proporciona más detalle del daño (Clouston 2001), sin embargo la complejidad del análisis cromosómico requiere de personal entrenado y mayor tiempo para el diagnostico (OECD 2004, Wolstenholme \& Burn 2001). Por otra parte, el análisis de micronúcleos provee mayor validez estadística ya que se registra miles de células binucleadas, mientras que las metafases se cuentan por cientos o menos.

La prueba de micronúcleos está validada internacionalmente como bioensayo para evaluar genotoxicidad de sustancias, exposiciones agudas y crónicas, y es una de las más usadas para identificar agentes cancerígenos (Murli 2003, Abrevaya et al. 2007).
La iniciativa internacional The International Collaborative Project on Micronucleus Frequency in Human Populations (HUMN), busca uniformizar el test de micronúcleos; allí se comparan resultados y se recopilan datos de frecuencias y variaciones de diferentes laboratorios en todo el mundo para establecer un protocolo estándar (Fenech 2007).

El HUMN establece ciertos criterios de selección para considerar una célula apta para el análisis estadístico. Dentro de esos criterios está el tener la membrana celular y citoplasma íntegros (Fenech 2003). En muchos laboratorios, para la observación de micronúcleos se utiliza la técnica estándar de preparación cromosómica de mamíferos a partir de linfocitos cultivados (Clouston 2001, Murli 2003). En esta técnica se emplea una solución hipotónica, necesaria para abrir las metafases y mejorar la visualización de cromosomas, eliminando además los eritrocitos. Ello es seguido por fijación de células y el lavado varias veces en soluciones de alcohol y ácido acético. Finalmente la muestra se deposita en láminas por goteo. El proceso de fijación y lavado, así como el goteo de la muestra en láminas, maltratan las membranas celulares y producen pérdida de citoplasma que dificulta el análisis de los micronúcleos. Por lo mencionado, la preparación citológica clásica del protocolo de micronúcleos es susceptible de optimizar.

En el presente trabajo reportamos modificaciones al protocolo estándar que mejoran la observación de las células, cumpliendo 
los criterios de selección según HUMN, facilitando el análisis estadístico y proporcionando confiabilidad y reproducibilidad por el incremento en el número y mejora en la calidad de los preparados citológicos.

1) La primera modificación es la purificación de linfocitos mediante el uso de Ficoll-Hypaque que separa los linfocitos de eritrocitos y demás componentes como paso previo al cultivo.

2) La segunda es la eliminación del uso de solución hipotónica para romper las membranas celulares. Este paso provocaba rompimiento de la membrana celular de linfocitos, y además se requería realizar varios lavados para limpiar el cultivo, lo que provoca pérdida de muestra.

3) La tercera modificación se refiere a la forma de preparar las láminas del cultivo, reemplazando el goteo de láminas por el frotis. Al gotear láminas a cierta distancia, en las preparaciones citológicas se rompen las membranas de los linfocitos (Clouston 2001). En consecuencia, se observan células con citoplasma muy irregular y disgregado; disminuyendo la calidad de las células para un análisis confiable, que cumpla los criterios establecidos por el HUMN. El uso de frotis, que mantiene el citoplasma intacto y mejora la visualización de células, permite un análisis más eficiente y rápido, al reducir el número de láminas necesarias para el conteo.

\section{Resumen del protocolo modificado}

Extracción de $3-5 \mathrm{~mL}$ de sangre periférica de un donante voluntario aparentemente sano y que se coloca por las paredes de un tubo falcon de $15 \mathrm{~mL}$ que contiene un volumen similar de Ficoll-Hypaque.

Centrifugación de la muestra de sangre a $3000 \mathrm{rpm}$ por 30 minutos para una separación por gradiente de densidad.

Siembra de la interfase de linfocitos en $5 \mathrm{~mL}$ de medio PBMax e incubación a $37^{\circ} \mathrm{C}$. De esta manera se eliminan los eritrocitos y el cultivo de linfocitos es más puro desde el inicio.

Después de $24 \mathrm{~h}$, se adiciona el mutágeno, la mitomicina $\mathrm{C}$ (MMC- Sigma MO503) $(0,16 \mu \mathrm{g} / \mathrm{mL})$ al control positivo. La MMC provocará quiebras cromosómicas que se evidenciarán por la formación de micronúcleos.

Después de 44 h, se agrega Citocalasina B (Sigma V6762) $(0,012 \mu \mathrm{g} / \mathrm{mL})$ a todos los tubos. La citocalasina B bloquea la citocinesis al interferir en la polimerización de microfilamentos de actina de manera que luego de la primera división celular se obtienen células binucleadas.

Cumplidas las $72 \mathrm{~h}$ de cultivo, se centrifuga a $300 \mathrm{rpm} / 5 \mathrm{~min}$ y se disgrega el taco celular suavemente. Se coloca una a dos gotas en una lámina y se hace un frotis, se fija la lámina por 5 minutos con una solución de metanol y acido acético 1:1. Luego se tiñe con Giemsa al 5\% por espacio de 8 minutos

$\mathrm{Al}$ realizar el conteo de células binucleadas obtenidas con la modificación, se obtuvo un Índice de División Nuclear (IDN) de 1,5 el cual se encuentra dentro del rango óptimo, según la HUMN (IDN= 1,3 - 2,0; Fenech 2007).

Los resultados con el protocolo modificado se muestran en la Tabla 1 y Tabla 2. El porcentaje obtenido en el control negativo sin MMC, se encuentra dentro del rango de la frecuencia basal reportada por otros laboratorios. La Figura 1 muestra las
Tabla 1. Número de células binucleadas por lámina (apropiadas para análisis según HUMN), con y sin modificación a la técnica estándar.

\begin{tabular}{lr}
\hline Número de binucleadas/lámina sin modificación & 64 \\
Número de binucleadas / lámina con modificación & 487 \\
\hline
\end{tabular}

Tabla 2. Frecuencia de micronúcleos obtenidos con el protocolo modificado, expresada en porcentajes e Índice de División Nuclear (IDN).

\begin{tabular}{lcc}
\hline \multicolumn{1}{c}{ Tratamiento } & Porcentaje (\%) & IDN \\
\hline Control negativo & 0,89 & 1,6 \\
Mitomicina C $(0,16 \mu \mathrm{g} / \mathrm{mL})$ & 12,05 & 1,3 \\
\hline
\end{tabular}

diferencias entre las células utilizando el protocolo estándar y aplicando las modificaciones.

En conclusión, gracias a las modificaciones aplicadas al protocolo original, se optimizó la técnica obteniendo un cultivo libre de eritrocitos y con preparados citológicos de mejor calidad. El número de células observadas es alrededor de 8 veces más que el protocolo estándar (un promedio de 487 binucleadas

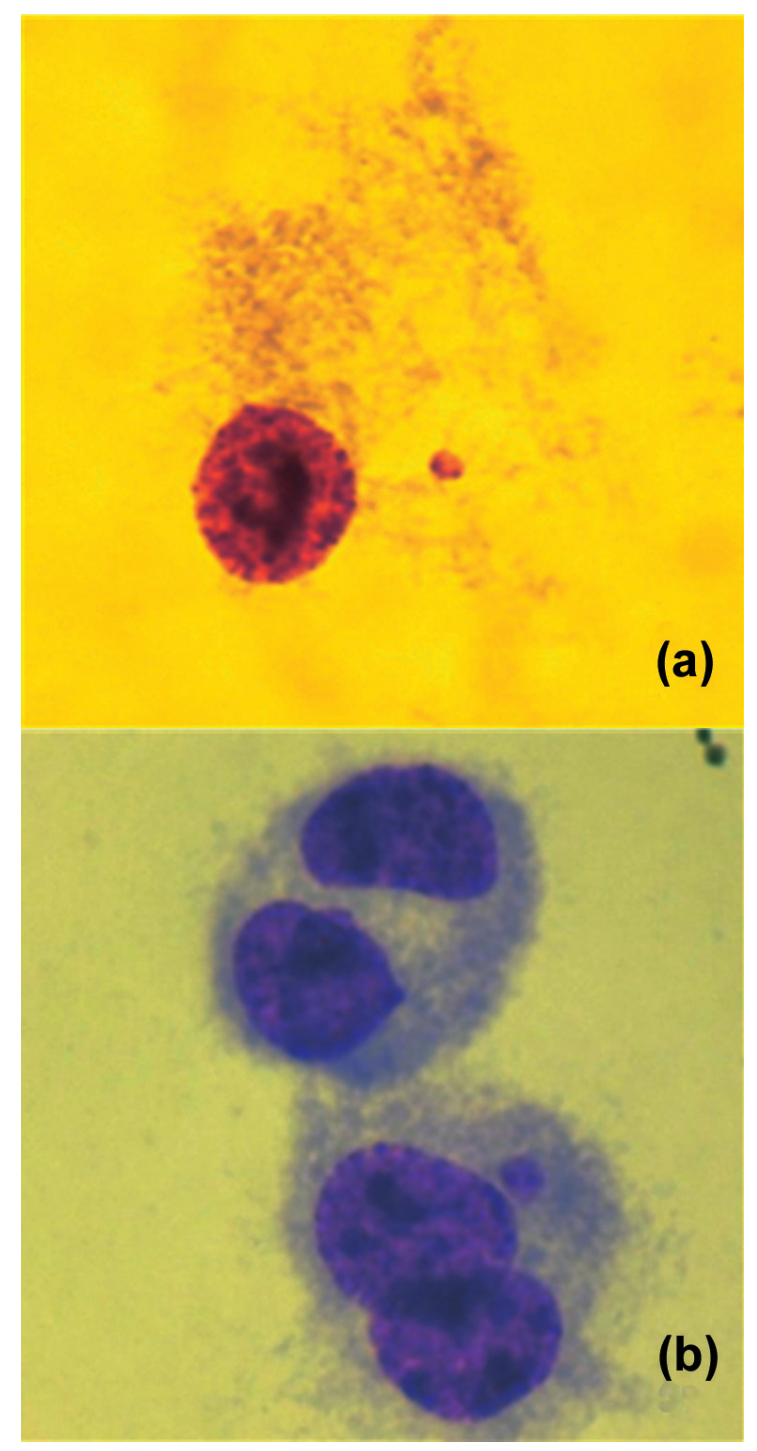

Figura 1. (a) Célula mononucleada con un micronúcleo, luego de la exposición a MMC, cultivada según el protocolo estándar sin modificar. (b) Células binucleadas inducidas con citocalasina B, con y sin micronúcleo, siguiendo las modificaciones al protocolo estándar y expuestas a mitomicina $\mathrm{C}$. 
frente a 64 binucleadas, por lámina), lo que permite obtener en menos tiempo las 2000 binucleadas necesarias para el análisis estadístico. Esta prueba estandarizada es utilizada actualmente en nuestro laboratorio para medir genotoxicidad de extractos vegetales entre otros.

\section{Agradecimientos}

Este trabajo fue posible debido al apoyo del Consejo $\mathrm{Na}$ cional de Ciencia y Tecnología (CONCYTEC), contrato 359-2006-CONCYTEC-OAJ y de la Facultad de Medicina de U. de San Martín de Porres (proyectos E10012007006, E10012009013).

\section{Literatura citada}

Abrevaya X.C., M.A. Carballo \& M.D. Mudry. 2007. The bone marrow micronucleus test and metronidazole genotoxicity in different strains of mice (Mus musculus) Genetics and Molecular Biology 30(4): 1139-1143

Clouston H.J. 2001. Lymphocyte culture. In: Rooney D.E. (ed) Human Cytogenetics: Constitutional Analysis - A Practical Approach 3rd ed. chap. 2, pp. 33-54. Oxford: Oxford University Press.
Fenech M. , W.P. Chang, M. Kirsch-Volders, et al. 2003. HUMN project: detailed description of the scoring criteria for the cytokinesis-block micronucleus assay using isolated human lymphocyte cultures. Mutation Research 534: 65-75.

Fenech M. 2007. Cytokinesis-block micronucleus cytome assay. Nature Protocols. 2 (5): 1084-1104.

Murli H. 2003. Screening Assay for Chromosomal Aberrrations in CHO Cells with Argentyn 23. Final Report en Covance 24742-0-437 SC 2003 Natural Immunogenics Corporation. Covance Laboratories Inc. 9200 Virginia, USA 08 April 2003 pp 1-15

OECD. 2004. Guideline for the testing of chemicals. Draft proposal for a new guideline 487: in vitro micronucleus test June 2004 Pp 1-13

Wolstenholme J. \& J. Burn. 2001. The application of cytogenetic investigations to clinical practice. In: Rooney D.E. (ed) Human Cytogenetics: Constitutional Analysis - A Practical Approach 3rd ed. Pp 129-174. 
